\title{
Assessment of Wind Power Density Based on Weibull Distribution in Region of Junin, Peru
}

\author{
Jose Galarza1, David Condezo$^{1}$, Becquer Camayo ${ }^{2}$, Enrique Mucha ${ }^{1}$ \\ ${ }^{1}$ Department of Electrical and Electronic Engineering, National University of the Center of Peru, Huancayo, Peru \\ ${ }^{2}$ Department of Applied Sciences, National University of the Center of Peru, Huancayo, Peru \\ Email: josegalarzalinares@gmail.com
}

How to cite this paper: Galarza, J., Condezo, D., Camayo, B. and Mucha, E. (2020) Assessment of Wind Power Density Based on Weibull Distribution in Region of Junin, Peru. Energy and Power Engineering, 12, 16-27.

https://doi.org/10.4236/epe.2020.121002

Received: December 3, 2019

Accepted: December 28, 2019

Published: December 31, 2019

Copyright $\odot 2020$ by author(s) and Scientific Research Publishing Inc. This work is licensed under the Creative Commons Attribution International License (CC BY 4.0).

http://creativecommons.org/licenses/by/4.0/

\begin{abstract}
This paper appraises the accuracy of methods for calculating wind power density (WPD), by comparing measurement values to the shape and scale parameters of the Weibull distribution (WD). For the estimation of WD parameters, the Graphical method (GP), Empirical method of Justus (EMJ), Empirical method of Lysen (EML), Energy pattern factor method (EPF), and Maximum likelihood method (ML) are used. The accuracy of each method was evaluated via multiple metrics: Mean absolute bias error (MABE), Mean absolute percentage error (MAPE), Root mean square error (RMSE), Relative root mean square error (RRMSE), Correlation coefficient (R), and Index of agreement (IA). The study's objective is to select the most suitable methods to evaluate the WD parameters ( $k$ and $c$ ) for calculating WDP in four meteorological stations located in Junin-Peru: Comas, Huasahuasi, Junin, and Yantac. According to the statistical index results, the ML, EMJ, and EML methods are the most accurate for each station, however, it is important to note that the methods do not perform equally well in all stations, presumably the graphical conditions and external factors play a major role.
\end{abstract}

\section{Keywords}

Accuracy, Meteorological Station, Statistical Indicator, Wind Energy

Potential, Wind Speed

\section{Introduction}

Renewable power capacity is increasing at a faster annual rate than all fossil fuels combined. In 2016, green energy comprised nearly $62 \%$ of the total power-generating capacity in the world, and more and more countries are using this technology [1]. According to renewable energy statistics, onshore wind energy in 
Peru is increasing, with the cumulative installed capacity expected to reach $372 \mathrm{MW}$ by the end of 2018 [2]. Wind resources have a variable and fluctuating behavior [3], however, such that an exhaustive evaluation of wind speeds is necessary for effective wind-energy harnessing. A standard approach for describing velocity is via the WD, a continuous probability distribution involving the two parameters of shape and scale [3] [4] [5] [6] [7]. The WD is used across multiple research areas concerned with wind velocity, extensive literature [3]-[15] used this type of distribution.

Reference [4] evaluated the effectiveness EMJ, EML, EPF, GP, ML, and Modified maximum likelihood method (MML) metrics to determine the shape and scale parameters of the WD to calculate the wind density power (WDP) at four weather stations in Canada, using three years of data. This study used the following statistical indicators: MABE, MAPE, RMSE, relative percentage error, RRMSE, and IA. The authors found that ML, EPF, EMJ, and EML are effective measurement methods. Reference [16] compared the results of five methods-GP, EMJ, ML, MML, and EPF-to determine scale and shape variables at the Babaurband wind mast in Sindh, Pakistan; the authors used R and RMSE to determine which of the WD parameter calculation methods gives the best result, and the authors found that EMJ, ML, MML, and EPF provide the optimal results when it comes to determining the scale and shape parameters of the WD. In reference [17], the authors presented four methods for estimating the Weibull parameters, namely, ML, rank regression method, mean standard deviation method, and power density method. R and RMSE were used to determine the relative precision of the parameter calculations provided by these methods. Reference [18] compared the standard deviation method and the power density method (empirical and energy pattern factor method) to calculate wind energy potential with five years of wind speed data from Zarrineh, Iran. Reference [19] evaluated the effectiveness of six methods-the moment method, empirical methods, GP, ML, MML, and EPF-to determine Weibull parameters for wind potential evaluation. The evaluation is compared via the Monte Carlo simulation, the Kolmogorov-Smirnov test, parameter error, RMSE, and wind energy error. The simulation test suggests that the ML, MML, and moment methods provide the most accurate calculations.

This paper addresses the WDP accuracy calculation in four locations in Junín, Peru, with the aim of establishing reliable methods for calculating wind resources (their available energy potential) in each area. It's important to mention that there are no prior studies of WDP in these areas. In the present study, five methods are used to calculate shape and scale variables and statistical indicators to determine the accuracy of WDP. The methods are GP, EMJ, EML, EPF, and ML.

The paper is organized as follows. In Section 2, the methods for estimating WD parameters and WDP are shown, also the four stations used as data sources for this paper, and the wind speed measurements are described. The analysis of results considering $k$ and $c$ parameters and statistics methods is presented in 
Section 3. Finally, the conclusion is presented in Section 4.

\section{Materials and Methods}

\subsection{Weibull Distribution}

Numerous probability distribution functions are available to evaluate wind speed frequency distributions. These functions include the Weibull, Rayleigh, Gamma, Pearson (V), Inverse Gaussian, and Log-normal functions [10]. The evaluation of wind energy is based on wind speed measurements. However, these are often variable, so it is useful to conduct the wind speed modelling as a function of certain parameters. The WD is widely accepted in the literature for the evaluation of wind energy [3]. The probability density of the WD is mathematically described with three parameters. With the minimal speed considered near zero, the distribution is then expressed as [9]:

$$
f(v)=\frac{k}{c}\left(\frac{v}{c}\right)^{k-1} \exp \left[-\left(\frac{v}{c}\right)^{k}\right]
$$

where $k$-shape parameter(dimensionless), $c$-scale parameters $(\mathrm{m} / \mathrm{s})$ and $v$-wind speed $(\mathrm{m} / \mathrm{s})$ for WD, $k$ and $c$ parameters are often used to characterize wind regimes because it has been found to provide a good fit with measured wind data.

The cumulative function is defined [9]:

$$
F(v)=1-\exp \left[-\left(\frac{v}{c}\right)^{k}\right]
$$

According to the literature, several methods are used to estimate the WD Parameters, the application of which is related to geographical conditions among other external factors [3]-[19]. The Graphical Method pursues the minimum last square error in the fitting process between measures and linear equations of the form $y=a x+b$. The Weibull parameters using this method can be calculated as [4] [5] [19]:

$$
\ln \{\ln [1-F(v)]\}=k \ln (v)-k \ln (c)
$$

In the group of empirical methods, the methods of Justus and Lysen are used. The method of Justus was formulated by C. G. Justus [20]; this is an experimental approach using a wind-powered generator system characterized by cut-in, rated, and cut-out speed to estimate the power output. The parameters of the Weibull are shown in [4] [18] [20]

$$
k=\left(\frac{\sigma}{\bar{v}}\right)^{-1.086}
$$

where $\sigma$-standard deviation of wind speed $(\mathrm{m} / \mathrm{s}), \bar{v}$-mean wind speed $(\mathrm{m} / \mathrm{s})$.

$$
c=\frac{\bar{v}}{\Gamma\left(1+\frac{1}{k}\right)}
$$

The method of Lysen uses experimental data to approximate the Gamma 
function $(\Gamma)$ by the next expression, as discussed in [21]. For the calculation of shape factor, the method of Justus is used.

$$
c=\bar{v}\left(0.568+\frac{0.4333}{k}\right)^{-\frac{1}{k}}
$$

The method of Energy Pattern Factor, uses $E_{p f}$ (aerodynamic parameter design) to calculate the $k$ parameter, as discussed in [4] [18] [19]. The $c$ parameter is calculated using the Justus formulation.

$$
\begin{gathered}
E_{p f}=\frac{\Gamma\left(1+\frac{3}{k}\right)}{\Gamma^{3}\left(1+\frac{1}{k}\right)} \\
k=1+\frac{3.69}{\left(E_{p f}\right)^{2}}
\end{gathered}
$$

Finally the method of Maximum Likehood is used. For this method, the likelihood function is used to estimate the Weibull parameters where $n$ is the number of observation, after several iterations the parameters are obtained; the mathematical expressions for the method are discussed in [4] [17] [19].

$$
\begin{gathered}
k=\left[\frac{\sum_{i=1}^{n} v_{i}^{k} \ln \left(v_{i}\right)}{\sum_{i=1}^{n} v_{i}^{k}}-\frac{\sum_{i=1}^{n} \ln \left(v_{i}\right)}{n}\right]^{-1} \\
c=\left[\frac{\sum_{i=1}^{n} v_{i}^{k}}{n}\right]^{\frac{1}{k}}
\end{gathered}
$$

The method for estimating wind power density is based on energy balances and Bernoulli's equation, the process of extracting the kinetic energy of the wind can be explained. The power per surface is dependent on the cube of wind speed and surface evaluation and $\rho$-air density $\left(\mathrm{kg} / \mathrm{m}^{3}\right)$. The measurement of WDP is obtained through a calculation as:

$$
\bar{P}_{v}=\frac{1}{2} \rho \bar{v}^{3}
$$

WDP is a measure of the energy that can be produced by wind turbine in a specific location. This measure can be calculated using the WD [4]:

$$
\bar{P}_{v}=\frac{1}{2} \rho c^{3} \Gamma\left(1+\frac{3}{k}\right)
$$

\subsection{Study Case: Region of Junin}

The onshore wind-generated energy in Peru is projected to be $372 \mathrm{MW}$ by the end of 2018 [2]. Since 2014, economic strategies have been developed by the Ministry of Energy and Mines to increase renewable energy capacity-for example, through energy auctions for solar and wind energy. Additionally, to incrementalize the massive increase in the use of electricity, and with the objec- 
tive of increasing the rural electrification coefficient, domestic photovoltaic panels and mini wind turbines have been installed in rural areas. However, there is either no information about the renewable energy potential of new projects or else the existing information is outdated. The focus of this study is the Junín region; this region is one of the most important in Peru when it comes to the economic development of the country. Because of the productivity of this region, it represents a large percentage of Peruvian energy demand. To date, however, no feasibility studies for projects using renewable energy sources such as wind and solar have been carried out. This study uses information provided by the National Meteorology and Hydrology Service of Peru (SENAMHI). SENAMHI indicates that there are 22 stations throughout the Junín region; situated $10 \mathrm{~m}$ up from the ground level, these stations have all been installed since 2003. This paper uses the wind measurements from four of these stations, in four areas with the highest average wind speed. These are: Comas, Huasahuasi, Junín, and Yantac. We use historical information from 2012 to 2017, basing our analysis on SENAMHI measurements that were made daily at 13:00 h. Table 1 shows the main characteristics of the meteorological stations in Junin-Peru.

Table 1. Meteorological station in region of Junin.

\begin{tabular}{|c|c|c|c|c|c|}
\hline Station & Latitude & Longitude & $\begin{array}{l}\text { Altitude } \\
\text { (m.a.s.l.) }\end{array}$ & $\begin{array}{c}\text { Mean Speed } \\
(\mathrm{m} / \mathrm{s})\end{array}$ & Town \\
\hline Acopalca & $11^{\circ} 55^{\prime} 39^{\prime \prime}$ & $75^{\circ} 06^{\prime} 59^{\prime \prime}$ & 3839 & 2.7 & Huancayo \\
\hline Chacapalca & $11^{\circ} 43^{\prime} 58^{\prime \prime}$ & $75^{\circ} 45^{\prime} 21^{\prime \prime}$ & 3752 & 2.3 & Chacapalca \\
\hline Comas & $11^{\circ} 11^{\prime} 44^{\prime \prime}$ & $75^{\circ} 07^{\prime} 45^{\prime \prime}$ & 3640 & 6.1 & Comas \\
\hline Huasahuasi & $11^{\circ} 15^{\prime} 42^{\prime \prime}$ & $75^{\circ} 37^{\prime} 15^{\prime \prime}$ & 2750 & 6.7 & Huasahuasi \\
\hline Huayao & $12^{\circ} 02^{\prime} 18^{\prime \prime}$ & $75^{\circ} 20^{\prime} 17^{\prime \prime}$ & 3360 & 2.6 & Huanchac \\
\hline Huaytapallana & $11^{\circ} 55^{\prime} 36^{\prime \prime}$ & $75^{\circ} 03^{\prime} 42^{\prime \prime}$ & 4584 & 1.7 & Huancayo \\
\hline Ingenio & $11^{\circ} 52^{\prime} 51^{\prime \prime}$ & $75^{\circ} 17^{\prime} 16^{\prime \prime}$ & 3390 & 2.9 & Santa Rosa de Ocopa \\
\hline Jauja & $11^{\circ} 47^{\prime} 12^{\prime \prime}$ & $75^{\circ} 29^{\prime} 13^{\prime \prime}$ & 3378 & 2.8 & Jauja \\
\hline Junin & $11^{\circ} 11^{\prime} 08^{\prime \prime}$ & $75^{\circ} 59^{\prime} 20^{\prime \prime}$ & 4120 & 8.2 & Junin \\
\hline La Oroya & $11^{\circ} 34^{\prime} 07^{\prime \prime}$ & $75^{\circ} 57^{\prime} 34^{\prime \prime}$ & 3910 & 3.2 & Santa Rosa de Saco \\
\hline Laive & $12^{\circ} 15^{\prime} 08^{\prime \prime}$ & $75^{\circ} 21^{\prime} 19^{\prime \prime}$ & 3860 & 5.2 & Yanacancha \\
\hline Marcapomacocha & $11^{\circ} 24^{\prime} 16^{\prime \prime}$ & $76^{\circ} 19^{\prime} 30^{\prime \prime}$ & 4447 & 2.8 & Marcapomacocha \\
\hline Puerto Ocopa & $11^{\circ} 08^{\prime} 01^{\prime \prime}$ & $74^{\circ} 15^{\prime} 01^{\prime \prime}$ & 690 & 3.1 & Rio Tambo \\
\hline Ricran & $11^{\circ} 32^{\prime} 22^{\prime \prime}$ & $75^{\circ} 31^{\prime} 26^{\prime \prime}$ & 3820 & 4.3 & Ricran \\
\hline San Juan de Jarpa & $12^{\circ} 07^{\prime} 30^{\prime \prime}$ & $75^{\circ} 25^{\prime} 55^{\prime \prime}$ & 3600 & 2.1 & San Juan de Jarpa \\
\hline Santa Ana & $12^{\circ} 00^{\prime} 15^{\prime \prime}$ & $75^{\circ} 13^{\prime} 15^{\prime \prime}$ & 3395 & 5.4 & El Tambo \\
\hline Satipo & $11^{\circ} 14^{\prime} 01^{\prime \prime}$ & $74^{\circ} 42^{\prime} 01^{\prime \prime}$ & 1370 & 2.8 & Satipo \\
\hline Tarma & $11^{\circ} 23^{\prime} 49^{\prime \prime}$ & $75^{\circ} 41^{\prime} 25^{\prime \prime}$ & 3000 & 5.7 & Tarma \\
\hline Viques & $12^{\circ} 09^{\prime} 47^{\prime \prime}$ & $75^{\circ} 14^{\prime} 07^{\prime \prime}$ & 3186 & 4 & Viques \\
\hline Yantac & $11^{\circ} 11^{\prime} 20^{\prime \prime}$ & $76^{\circ} 24^{\prime} 16^{\prime \prime}$ & 4617 & 6.3 & Marcapomacocha \\
\hline
\end{tabular}


The Andes are the highest mountains in the world. These peaks modify the climate of the region that hosts them, and several areas within Junín do have a modified climate. For example, the coastal areas have a typical summer climate, whereas the areas near the Andes that have a rainy and cloudy summer climate. Both types of weather occur during the first four months of the year.

\subsection{Evaluation of Weibull Parameters}

The authors reviewed previous literature about methods used to estimate the WD parameters (shape and scale) and WDP. The data obtained from the meteorological station of Junin were subjected to these methods for purposes of evaluation. The calculus of indicators and data processing were performed using the scripts in Matlab (2017b). In daily analysis, historical information from 2012 to 2017 were used, with one measurement per day. The WD parameters were calculated using five methods: EMJ, EPF, ML, GP, and EML.

In order to determine the relative precision of each of the five methods the statistical indicators were used to assess the accuracy of each of them. The $k$ and $c$ variables were used to calculate the WDP in comparison with the measured data, MAPE and MABE indicators show the general degree of error of each of the methods; for a more precise diagnostic, RMSE is used. RMSE gives the model's precision as a result of contrasting the Weibull function and the measured data [4]. The RRMSE represents the precision of the model with qualifications like excellent, good, fair, and poor according to its value [21] [22]. The MAPE and RRMSE are expressing in percentages, whereas MABE and RMSE are expressed in $\mathrm{W} / \mathrm{m}^{2}$. Correlation coefficient $\mathrm{R}$ is a statistical index that calculates the strength of the linkage between the WDP calculated by the WD and the WDP calculated by measures; this index is in the range of -1 to 1 . The IA or Willmont index is a normalized metric used to assess the model prediction error [23] [24].

The results of statistical indicators for each meteorological station show the convenience methods for the estimation of parameters. These selected methods are evaluated in more detail in what follows. The evolution of the $k$ and $c$ parameters is tracked over a 72-month period to determine the fluctuation of the parameters, with the average value per month being used for this analysis.

\section{Results}

This section describes the approaches used first to estimate and then to evaluate the $k$ and $c$ parameters for the four meteorological stations in the Junin region of Peru. The objective is to find the most convenient method to estimate the accuracy of the $\mathrm{WD}$, with statistical indicators being used for the performance evaluation of the methods.

\subsection{Estimation of the Weibull Parameters}

The $k$ and $c$ parameters were estimated using five methods: EMJ, EPF, ML, GP, 
and EML. For the Yantac station, the data were collected from 2014 (April) to 2017 (December), but for all the other stations, data were collected from 2012 (January) to 2017 (December). In the case of Comas station, the Weibull parameters are calculated using a total of 2191 wind measurements; for the $k$ parameter, the EPF method shows $16 \%$ variation with respect to mean values, hence this method is likely not accurate enough to estimate the WD parameters; by way of comparison, all the methods used to estimate the $c$ parameter show variations of less than $3 \%$ with respect to the mean value. For Huasahuasi Station, 2190 wind measurements were used to estimate the Weibull parameters; for the $k$ parameter, the GP method shows $9 \%$ variation with respect to mean values; all the methods used to estimate the $c$ parameter show variations of less than $1 \%$ with respect to the mean value. In the case of Junin Station, the Weibull parameters were calculated using 2191 wind measurements; in this case all results for both parameters show variation of less than $1 \%$ with respect to the mean value. Finally for Yantac Station the parameters of the WD were estimated with 1404 wind measurements. In this case, the shape parameter in the GP method shows $17 \%$ variation with respect to mean values and the EPF method shows $11 \%$ variation. All methods used to estimate the $c$ parameter show variations of less than $1 \%$ with respect to the mean value. The results of the five methods for all station are shown in Table 2.

\subsection{Statistical Indicators for $\boldsymbol{k}$ and $c$ Performance}

Table 3 shows the statistical indicators for the accuracy in estimating WDP using Weibull parameters. In the case of Comas station, the greatest accuracy in estimating WDP is achieved using the EMJ and EML methods; the values of 16.913 and 17.175 for RRMSE indicate that these methods have good model precision. For Huasahuasi station, the highest agreement is attained when the ML method is used to estimate the WD parameters; also, EMJ and EML show high agreement as well; the value of 3.836 for RRMSE indicates excellent model precision. In the case of Junin station we found that the highest agreement is attained

Table 2. Methods used to estimate Weibull parameters.

\begin{tabular}{|c|c|c|c|c|c|c|}
\hline \multirow[t]{2}{*}{ Station } & \multirow[t]{2}{*}{ Variable } & \multicolumn{5}{|c|}{ Method } \\
\hline & & GP & EMJ & EML & EPF & $\mathrm{ML}$ \\
\hline \multirow{2}{*}{ Comas } & $k$ & 4.539 & 4.424 & 4.424 & 3.619 & 4.570 \\
\hline & $c$ & 6.736 & 6.771 & 6.767 & 6.848 & 6.758 \\
\hline \multirow{2}{*}{ Huasahuasi } & $k$ & 2.800 & 3.153 & 3.153 & 3.033 & 3.213 \\
\hline & $c$ & 7.394 & 7.337 & 7.336 & 7.351 & 7.311 \\
\hline \multirow{2}{*}{ Junin } & $k$ & 3.836 & 3.703 & 3.703 & 3.290 & 3.690 \\
\hline & $c$ & 8.844 & 8.891 & 8.887 & 8.946 & 8.886 \\
\hline \multirow{2}{*}{ Yantac } & $k$ & 4.175 & 3.547 & 3.547 & 3.160 & 3.401 \\
\hline & $c$ & 7.180 & 7.308 & 7.305 & 7.351 & 7.313 \\
\hline
\end{tabular}


Table 3. Accuracy in estimation Weibull parameters by statistics index.

\begin{tabular}{|c|c|c|c|c|c|c|c|}
\hline \multirow[t]{2}{*}{ Station } & \multirow[t]{2}{*}{ Method } & \multicolumn{6}{|c|}{ Index } \\
\hline & & MAPE (\%) & $\operatorname{MABE}\left(\mathrm{W} / \mathrm{m}^{2}\right)$ & $\operatorname{RMSE}\left(\mathrm{W} / \mathrm{m}^{2}\right)$ & RRMSE (\%) & $\mathrm{R}$ & IA \\
\hline \multirow{5}{*}{ Comas } & GP & 0.010 & 0.578 & 1.272 & 19.299 & 0.996 & 0.970 \\
\hline & EMJ & 0.012 & 0.522 & 1.132 & 17.175 & 0.997 & 0.973 \\
\hline & EML & 0.011 & 0.516 & 1.114 & 16.913 & 0.997 & 0.973 \\
\hline & EPF & 0.010 & 1.651 & 3.435 & 52.124 & 0.967 & 0.915 \\
\hline & ML & 0.014 & 0.620 & 1.368 & 20.755 & 0.996 & 0.968 \\
\hline \multirow{5}{*}{ Huasahuasi } & GP & 0.006 & 1.955 & 3.422 & 37.802 & 0.974 & 0.916 \\
\hline & EMJ & 0.001 & 0.347 & 0.656 & 7.242 & 0.999 & 0.985 \\
\hline & EML & 0.002 & 0.343 & 0.647 & 7.150 & 0.999 & 0.985 \\
\hline & EPF & 0.003 & 0.819 & 1.482 & 16.370 & 0.995 & 0.965 \\
\hline & ML & 0.004 & 0.207 & 0.347 & 3.836 & 1.000 & 0.991 \\
\hline \multirow{5}{*}{ Junin } & GP & 0.004 & 0.910 & 1.691 & 10.991 & 0.998 & 0.977 \\
\hline & EMJ & 0.006 & 0.738 & 1.292 & 8.400 & 0.999 & 0.981 \\
\hline & EML & 0.005 & 0.727 & 1.264 & 8.218 & 0.999 & 0.981 \\
\hline & EPF & 0.003 & 2.625 & 4.540 & 29.506 & 0.982 & 0.932 \\
\hline & ML & 0.005 & 0.725 & 1.265 & 8.223 & 0.999 & 0.981 \\
\hline \multirow{5}{*}{ Yantac } & GP & 0.004 & 1.767 & 3.612 & 41.838 & 0.974 & 0.925 \\
\hline & EMJ & 0.004 & 0.361 & 0.687 & 7.962 & 0.999 & 0.985 \\
\hline & EML & 0.004 & 0.355 & 0.671 & 7.776 & 0.999 & 0.985 \\
\hline & EPF & 0.004 & 1.508 & 2.814 & 32.599 & 0.982 & 0.935 \\
\hline & ML & 0.003 & 0.616 & 1.222 & 14.155 & 0.997 & 0.974 \\
\hline
\end{tabular}

with EMJ, EML, and ML when it comes to calculating the WD parameters; the values of 8.4, 8.218, and 8.223 for RRMSE indicate excellent model precision. Finally for Yantac station we found that the highest agreement was attained when the EMJ and EML methods were used to estimate the WD parameters, the values of 7.962 and 7.776 for RRMSE indicate excellent model precision. All good and excellent ratings are according to the criteria as shown in [21] [22] [25].

The calculations by year were used to develop the analysis more fully. In the case of Comas station EMJ and EML method were chosen, the evolution in the data patterning over 72 months were evaluated for the $k$ and $c$ parameters using both methods; these parameters have similar values; our findings confirm that the EMJ and EML methods are the most accurate for WDP calculations. For Husahuasi station the analysis was used for a more detailed assessment of the ML, EMJ, and EML methods; the three methods show the same tendencies for both parameters over time. Overall, we found that ML, EMJ, and EML methods have the greatest accuracy for WDP calculation. In the case of Junin station the analysis was used for the EMJ, EML, and ML methods to develop the analysis 
more fully; the three methods reveal the same tendencies for both parameters; overall, we found that the ML, EMJ, and EML methods have the greatest accuracy for WDP calculation. Finally for Yantac station the analysis was used for the EMJ and EML methods to develop the analysis more fully; the evolution from year to year was evaluated for the $k$ and $c$ parameters using both methods; the three methods show the same tendencies for both parameters; overall, we found that EMJ and EML methods have the most accuracy for WDP calculation. For all stations the evaluation results by year are displayed in Table 4 .

\subsection{Estimation of Wind Power Density}

This section estimates the WDP with the chosen methods, as a function of the results from an analysis based on statistical indicators. For a more detailed analysis, the use of wind turbine characteristics would be used. Table 5 shows the results for all the meteorological stations for wind power density with measurements (WDP - m) and wind power density with the Weibull distribution (WDP - d). The results are the averaged annual value from 2012 to 2017 in all stations

Table 4. Weibull parameters evolution.

\begin{tabular}{|c|c|c|c|c|c|c|c|c|}
\hline \multirow[t]{2}{*}{ Station } & \multirow[t]{2}{*}{ Method } & \multirow[t]{2}{*}{ Variable } & \multicolumn{6}{|c|}{ Year } \\
\hline & & & 2012 & 2013 & 2014 & 2015 & 2016 & 2017 \\
\hline \multirow{4}{*}{ Comas } & EMJ & $k$ & 4.2138 & 4.5722 & 4.0236 & 4.5059 & 4.8256 & 4.9984 \\
\hline & EML & $k$ & 4.2138 & 4.5722 & 4.0236 & 4.5059 & 4.8256 & 4.9984 \\
\hline & EMJ & $c$ & 6.8914 & 6.5627 & 6.2910 & 6.6252 & 7.1475 & 7.0839 \\
\hline & EML & $c$ & 6.8878 & 6.5589 & 6.2880 & 6.6214 & 7.1432 & 7.0795 \\
\hline \multirow{6}{*}{ Huasahuasi } & ML & $k$ & 3.7308 & 3.3100 & 3.2020 & 3.2005 & 3.1670 & 2.9125 \\
\hline & EMJ & $k$ & 3.6450 & 3.2284 & 3.1237 & 3.1392 & 3.1155 & 2.8654 \\
\hline & EML & $k$ & 3.6450 & 3.2284 & 3.1237 & 3.1392 & 3.1155 & 2.8654 \\
\hline & ML & $c$ & 7.3031 & 6.8387 & 7.4429 & 7.4633 & 7.5288 & 7.2677 \\
\hline & EMJ & $c$ & 7.3255 & 6.8643 & 7.4683 & 7.4850 & 7.5529 & 7.3100 \\
\hline & EML & $c$ & 7.3227 & 6.8627 & 7.4670 & 7.4836 & 7.5516 & 7.3096 \\
\hline \multirow{6}{*}{ Junin } & ML & $k$ & 3.6756 & 3.9960 & 4.1782 & 4.0218 & 3.6271 & 3.2081 \\
\hline & EMJ & $k$ & 3.5805 & 3.8716 & 4.1788 & 4.1683 & 3.7692 & 3.2326 \\
\hline & EML & $k$ & 3.5805 & 3.8716 & 4.1788 & 4.1683 & 3.7692 & 3.2326 \\
\hline & ML & $c$ & 9.6353 & 9.1121 & 8.9848 & 8.7853 & 8.5872 & 8.1208 \\
\hline & EMJ & $c$ & 9.6479 & 9.1271 & 8.9940 & 8.7842 & 8.5865 & 8.1204 \\
\hline & EML & $c$ & 9.6445 & 9.1230 & 8.9894 & 8.7797 & 8.5829 & 8.1186 \\
\hline \multirow{4}{*}{ Yantac } & EMJ & $k$ & - & - & 2.9940 & 3.3970 & 3.9044 & 4.8229 \\
\hline & EML & $k$ & - & - & 2.9940 & 3.3970 & 3.9044 & 4.8229 \\
\hline & EMJ & $c$ & - & - & 6.2656 & 7.2340 & 7.9236 & 7.4933 \\
\hline & EML & $c$ & - & - & 6.2648 & 7.2319 & 7.9200 & 7.4887 \\
\hline
\end{tabular}


Table 5. Wind power density in meteorological stations.

\begin{tabular}{cccc}
\hline lightaqua Station & Method & WPD - m & WPD - d \\
\hline \multirow{2}{*}{ Comas } & EMJ & 28.495 & 28.662 \\
& EML & 28.495 & 28.615 \\
\hline Huasahuasi & ML & 38.952 & 38.837 \\
\hline \multirow{2}{*}{ Junin } & EMJ & 66.944 & 67.009 \\
& EML & 66.944 & 66.929 \\
Yantac & ML & 66.944 & 66.973 \\
& EMJ & 60.009 & 59.402 \\
\hline
\end{tabular}

except the Yantac station, for which data from 2014 to 2017 were used. The values of the calculation using measurements and using the WD are closely correlated. This conclusion is confirmed by the high correlation revealed through the $\mathrm{R}$ and IA coefficients.

\section{Conclusions}

This paper has investigated five well-know methods for estimating the Weibull distribution parameters and wind power density, statistical metrics are used to find the most convenient method to estimate the accuracy of the Weibull distribution. The evaluation was carried out in four locations in region of Junin-Peru with data from SENAMHI for the years 2012-2017. The following conclusion is made:

- According to the results of the statistical indicators, the ML, EMJ and EML proved to be the most suitable methods for calculating wind power density in each of the four locations in region of Junin.

- The wind power density calculated using experimental data and Weibull distribution parameter has a difference less or equal than $1 \%$.

- The Weibull distribution considering the shape and scale parameters presents accuracy calculation of the wind power density, independently of the three suitable methods found by the authors (ML, EMJ and EML), the results are very close to each other.

\section{Acknowledgements}

The authors thank the National University of the Center of Peru for support in carrying out this research.

\section{Conflicts of Interest}

The authors declare no conflicts of interest regarding the publication of this paper.

\section{References}

[1] REN21. Renewables Global Futures Report: Great Debates towards 100\% Renewable 
Energy. https://www.ren21.net/reports/global-futures-report

[2] IRENA. Renewable Energy Statistics 2019.

https://www.irena.org/Statistics/View-Data-by-Topic/Capacity-and-Generation/Re gional-Trends

[3] Weisser, D. (2003) A Wind Energy Analysis of Grenada: An Estimation Using the "Weibull" Density Function. Renewable Energy, 28, 1803-1812. https://doi.org/10.1016/S0960-1481(03)00016-8

[4] Mohammadi, K., Alavi, O., Mostafaeipour, A., Goudarzi, N. and Jalilvand, M. (2016) Assessing Different Parameters Estimation Methods of Weibull Distribution to Compute Wind Power Density. Energy Conversion and Management, 108, 322-335. https://doi.org/10.1016/j.enconman.2015.11.015

[5] Lu, L., Yang, H.X. and Burnett, J. (2002) Investigation on Wind Power Potential on Hong Kong Islands-An Analysis of Wind Power and Wind Turbine Characteristics. Renewable Energy, 27, 1-12. https://doi.org/10.1016/S0960-1481(01)00164-1

[6] Seguro, J.V. and Lambert, T.W. (2000) Modern Estimation of the Parameters of the Weibull Wind Speed Distribution for Wind Energy Analysis. Journal of Wind Engineering and Industrial Aerodynamics, 85, 75-84. https://doi.org/10.1016/S0167-6105(99)00122-1

[7] Persaud, S., Flynn, D. and Fox, B. (1999) Potential for Wind Generation on the Guyana Coastlands. Renewable Energy, 18, 175-189.

https://doi.org/10.1016/S0960-1481(98)00793-9

[8] De, A.R. and Musgrove, L. (1988) The Optimization of Hybrid Energy Conversion Systems Using the Dynamic Programming Model-Rapsody. International Journal of Energy Research, 12, 447-457. https://doi.org/10.1002/er.4440120309

[9] Katinas, V., Marčiukaitis, M., Gecevičius, G. and Markevičius, A. (2017) Statistical Analysis of Wind Characteristics Based on Weibull Methods for Estimation of Power Generation in Lithuania. Renewable Energy, 113, 190-201. https://doi.org/10.1016/j.renene.2017.05.071

[10] Brano, V.L., Orioli, A., Ciulla, G. and Culotta, S. (2011) Quality of Wind Speed Fitting Distributions for the Urban Area of Palermo, Italy. Renewable Energy, 36, 1026-1039. https://doi.org/10.1016/j.renene.2010.09.009

[11] Aukitino, T., Khan, M.G.M. and Ahmed, M.R. (2017) Wind Energy Resource Assessment for Kiribati with a Comparison of Different Methods of Determining Weibull Parameters. Energy Conversion and Management, 151, 641-660. https://doi.org/10.1016/j.enconman.2017.09.027

[12] Fyrippis, I., Axaopoulos, P.J. and Panayiotou, G. (2010) Wind Energy Potential Assessment in Naxos Island, Greece. Applied Energy, 87, 577-586. https://doi.org/10.1016/j.apenergy.2009.05.031

[13] Islam, M.R., Saidur, R. and Rahim, N.A. (2011) Assessment of Wind Energy Potentiality at Kudat and Labuan, Malaysia Using Weibull Distribution Function. Energy, 36, 985-992. https://doi.org/10.1016/j.energy.2010.12.011

[14] Celik, A.N. (2004) A Statistical Analysis of Wind Power Density Based on the Weibull and Rayleigh Models at the Southern Region of Turkey. Renewable Energy, 29, 593-604. https://doi.org/10.1016/j.renene.2003.07.002

[15] Ali, S., Lee, S.-M. and Jang, C.-M. (2018) Statistical Analysis of Wind Characteristics Using Weibull and Rayleigh Distributions in Deokjeok-Do Island-Incheon, South Korea. Renewable Energy, 123, 652-663. https://doi.org/10.1016/j.renene.2018.02.087 
[16] Khahro, S.F., Tabbassum, K., Soomro, A.M., Dong, L. and Liao, X.Z. (2014) Evaluation of Wind Power Production Prospective and Weibull Parameter Estimation Methods for Babaurband, Sindh Pakistan. Energy Conversion and Management, 78, 956-967. https://doi.org/10.1016/j.enconman.2013.06.062

[17] Ahmed, S.A. (2013) Comparative Study of Four Methods for Estimating Weibull Parameters for Halabja, Iraq. International Journal of Physical Sciences, 8, 186-192.

[18] Mohammadi, K. and Mostafaeipour, A. (2013) Using Different Methods for Comprehensive Study of Wind Turbine Utilization in Zarrineh, Iran. Energy Conversion and Management, 65, 463-470. https://doi.org/10.1016/j.enconman.2012.09.004

[19] Chang, T.P. (2011) Performance Comparison of Six Numerical Methods in Estimating Weibull Parameters for Wind Energy Application. Applied Energy, 88, 272-282. https://doi.org/10.1016/j.apenergy.2010.06.018

[20] Justus, C.G., Hargraves, W.R. and Yalcin, A. (1976) Nationwide Assessment of Potential Output from Windpowered Generators. Journal of Applied Meteorology, 15, 673-678. https://doi.org/10.1175/1520-0450(1976)015<0673:NAOPOF>2.0.CO;2

[21] Lysen, E.H. (1983) Introduction to Wind Energy. Consultancy Services Wind Energy Developing Countries.

[22] Li, M.-F., Tang, X.-P., Wu, W. and Liu, H.-B. (2013) General Models for Estimating Daily Global Solar Radiation for Different Solar Radiation Zones in Mainland China. Energy Conversion and Management, 70, 139-148. https://doi.org/10.1016/j.enconman.2013.03.004

[23] Legates, D.R. and McCabe Jr., G.J. (1999) Evaluating the Use of "Goodness-of-Fit" Measures in Hydrologic and Hydroclimatic Model Validation. Water Resources Research, 35, 233-241. https://doi.org/10.1029/1998WR900018

[24] Willmott, C.J. (1981) On the Validation of Models. Physical Geography, 2, 184-194. https://doi.org/10.1080/02723646.1981.10642213

[25] Jamieson, P.D., Porter, J.R. and Wilson, D.R. (1991) A Test of the Computer Simulation Model ARCWHEAT1 on Wheat Crops Grown in New Zealand. Field Crops Research, 27, 337-350. https://doi.org/10.1016/0378-4290(91)90040-3 